\section{AN INTERESTING CASE OF MULTIPLE RETROPERITONEAL IIYDATID CYSTS.}

BY FRANK COLE MADDEN, M.D. Melb., F.R.C.S. ENG., PROFESSOR OF SURGERY, EGYPTIAN GOVERNMENT SCHOOL OF MEDICINE; SENIOR SURGEON, KASR-EI-AINY HOSPITAL, GarRo.

HYDATID disease is rare in Egypt; so rare, indeed, that in a note published in the Intercolonial Medrcal Joumal of Australasia of March 20th, 1904, I quoted figures showing that, in an experience of 7000 cases in hospital practice and in the post-mortem room, the incidence of hydatid was only 1 per 1000. When it does occur, however, it not infrequently develops in unusual situations. In confirmation of this statement I would like to make a somewhat detailed reference to the following case of retroperitoneal infection which presented several features of gynæcological as well as of surgical interest. My first introduction to this patient, a young Egyptian woman, was on Oct. 4th, 1899, when she presented herself at Kasr-el-Ainy Hospital to be treated for prolapse of the uterus. Abdominal hysteropexy was advised and on opening the abdomen through the linea alba an elongated tense swelling was found in the substance of the broad ligament behind and to the right of the uterus. The uterus having been pulled up out of the pelvis by a volsellum forceps, an incision was made over the swelling, after protecting the surrounding area with gauze, and a clear fluid containing $a$ number of minute hydatid cysts was evacuated. The whole of the mother cyst and its adventitious capsule of connective tissue was then completely removed and the divided broad ligament was restored by a continuous suture. Finally, though it was hardly necessary now that the cause of the prolapse had been removed, abdominal hysteropexy was performed. On the patient's discharge from hospital three weeks later the uterus was found to be in good position and no further swelling could be detected in either broad ligament. ${ }^{1}$

On Jan. 12th, 1904, the patient was again admitted with a very hard rounded lump in the right lower abdomen. Not being able to trace her previous history for the moment we thought we had to deal with a uterine fibroid; but on opening the abdomen through the right rectus sheath a thickwalled hydatid cyst completely covered by peritoneum was found to the right of the site of the original cyst. This second cyst was much larger than the first and was adherent to the adjacent coils of intestine and to the appendix by recent peritonitic adhesions. These having been separated the entire cyst was removed and a pedicle of connective tissue which ran down deep into the pelvis was ligatured off. The divided posterior layer of peritoneum was sutured and the abdominal wall was closed in layers. At this operation it was noticed that the uterus was well fixed by a short, strong, fibrous adhesion to the old scar in the anterior abdominal wall, a very satisfactory result nearly five years after the hysteropexy. After this, as was the case with the first operation, convalescence was uninterrupted by any complication and we saw no more of the patient until the end of 1907, when she returned with a hard rounded swelling in the right iliac and lumbar regions. The scars of the two former operations were quite small and the abdominal wall had firmly healed. Dr. R. S. Dobbin, under whose care she was now admitted, was good enough to ask me to operate, and on Dec. 9th, 1907, an incision was made in the right semilunar line and the abdomen again opened through the outer edge of the rectus sheath. We at once came upon a retroperitoneal tumour which was pushing the cæcum in front of it towards the abdominal incision. The appendix was tightly stretched across the top of the tumour and was removed between ligatures. The peritoneum over the mass was opened up and a thick-walled calcified hydatid cyst was removed. On further exploration a still larger lobulated mass of cysts of similar character was exposed and taken away, together with a few yellow calcified hydatid deposits on the mesocolon. It was evident that there was now a commencing general infection of the peritoneum, as several of these small hydatid tubercles were seen on the serous coat of the

1 Records of the Cairo School of Medicine, vol. i., 1901. intestines and on the mesentery in the neighbourhood of the incision.

Fourteen days after this third operation it was noticed that the abdomen was gradually increasing in size. At first sight this appeared to be due to free fluid in the peritoneal cavity, but on careful examination a cystic swelling could be made out on the right side, apparently extending from the pelvis up as far as the umbilicus, or even higher, and a harder, more circumscribed mass in the left lumbar region, feeling not unlike a displaced kidney. (The urine contained no albumin, and 1500 cubic centimetres were passed in the 24 hours.) The patient complained mainly of pain over the lower ribs on each side and oppression in her breathing. As the swelling showed no signs of decreasing in size an exploratory laparotomy was done on Jan. 11th, 1908, and the abdomen was opened for the fourth time by a long incision in the right rectus sheath ending below in the scar of the third operation. The transverse colon was seen to be pushed downwards and the ascending colon inwards by a large retro. peritoneal cyst. On incising the posterior parietal peritoneum this cyst was found to extend nearly to the brim of the pelvis below and passed upwards out of sight behind the right lobe of the liver. Its lower connexions in the retroperitoneal connective tissue space were fairly easily separated though the cyst extended well beyond the middle line and filled the whole right lumbar region. It, then ran upwards behind the liver, over the right kidney, and finally (after evacuating its contents) it was found to be firmly attached on the front of the spinal column to the crura of the diaphragm. Here strong fibrous bands had to be ligatured off before the cyst could be removed. Laterally the cyst spread on to the dome of the diaphragm on the right: side and in the substance of this muscle were imbedded two separate thick-walled cysts full of daughter cysts. To effecto the removal of these smaller cysts the pleural cavity had to be opened and considerable difficulty was experienced in delivering the upper end of the main cyst as well as in enucleating the outlying groups in the diaphragm. At one point the cyst had formed a firm attachment, about two inches broad, with the lower edge of the right lobe of the liver, probably due to adhesions between the peritoneum covering the cyst and that covering the liver. So firm was this adhesion that the liver substance had to be cut through to liberate it and catgut sutures had to be inserted to control the resulting hæmorrhage from the cut surface. The mass on the left side was found to be composed of numerous cysts in the gastro-colic and gastrosplenic omentum. These were removed, as also several other cysts of varying size in the mesentery. Many gritty tubercles were seen on the serous lining of the small intestines and throughout the mesentery. The pleural cavity was then shut off from the abdomen by sutures and a drainage tube was inserted on to the upper surface of the restored diaphragm through the seventh intercostal space. A free counter opening was made posteriorly below the border of the ribs and a tube was inserted into the space from which the main body of the cyst had been removed. The posterior parietal peritoneum was restored as completely as possible and the whole abdomen was freely irrigated with normal saline solution. Finally, a large glass drainage-tube was placed in Douglas's pouch and secured in the lower end of the abdominal incision which was then carefully closed in layers. On subsequent examination the main cyst was found to be filled to distension with a dark brownish-yellow fluid in which floated the softened remains of numerous large hydatids. Floating also on the surface of the fluid and visible even through the cyst wall were many large globules of bright red pigment exactly like red iodide of mercury in colour which on subsequent investigation by Professor $\mathrm{W}$. $\mathrm{H}$. Wilson proved to be pure hæmatoidin. Unfortunately, the operation for the removal of this enormous cyst took such a long time and involved so much manipulation in the splanchnic area that in spite of all our efforts the patient died a few hours afterwards.

The post-mortem examination by Professor A. R. Ferguson, besides confirming the anatomical relations of the cyst already described, showed that the right lobe of the liver was very much atrophied from pressure of the cyst; indeed, it consisted mainly of a mass of fibrous tissue. The left lobe was enormously enlarged by compensatory hypertrophy and filled the whole of the left subdiaphragmatic area, flattening out the spleen beneath it. The substance of the spleen was 
much softened. The right kidney was long and thin and almost flattened out of existence by the weight of the superincumbent cyst. The uterus was somewhat enlarged and its fundus was closely adherent to the anterior abdominal wall in the old median incision. A piece of small intestine was fixed to this adhesion in its whole length and several other knuckles of bowel were adherent by small bands around the median scar. The rest of the necropsy presented no special features of interest. Thus the fundus of the uterus had remained attached to the anterior abdominal wall without any stretching of the scar for more than eight years. It seems likely that the large cyst had been lying comparatively empty along the front of the spinal column for some time, and its relatively sudden enlargement was due, in all probability, to the occurrence of suppuration within it.

Though the native Egyptian lives with his animals a great deal the rarity of hydatid disease may be understood by quoting a paragraph from the note on the subject to which reference has already been made as follows: "Professor Looss has never found the tænia echinococcus in a stray dog in and about Cairo but discovered it once in a small pet-dog. It is possible that in the villages the dogs may harbour tania, though there is but little chance of their being infected with the disease, as no slaughtering of animals affected with the disease in the cysticercus form takes place Very little meat is eaten by the country people and the only killing for food is done at the abattoirs. Even should a pariah dog become infected by eating cysts from cattle or sheep he is so shy and wild that man runs very little risk of infection from him. He is the great scavenger of the village and is never fondled or made a pet of in any way. The larval stage of the tænia echinococcus is occasionally met with in sheep and goats and is exceedingly common in cattle and camels. This localisation to the herbivora is common in all countries in which the disease is found." 2

Cairo.

\section{ON THE ANATOMICAL VARIETIES AND THEIR BEARING ON THE TREATMEN'T OF PATHOLOGICAL CONDITIONS OF THE PALATINE TONSILS.}

BY G. SECCOMBE HETT, M.B. LOND., F.R.C.S. ENG., ASSISTANT SURGEON TO THE LONDON THROAT HOSPITAL; OUT-PATIENT ASSISTANI', EAR AND THROAT DEPARTMENT, UNIVERSITY COLLEGE HOSPITAL, LONDON.

THE palatine tonsils present several well-marked anatomical varieties and embryonic remains. As these are easily to be recognised in many cases, even in pathological tonsils, and have an important bearing upon treatment, the following short account of the varieties commonly met with and an explanation of their causation from embryological and comparative anatomical data has been written. The tonsil is developed in the second cleft recess during the fourth month of fæetal life, the faucial pillars between which it lies representing portions of the second and third branchial arches. The hypoblastic recess opens into the pharynx as a funnelshaped cavity with widely open mouth and terminates under cover of the solt palate as a narrow canal - the supratonsillar fossa. On the outer wall of this hypoblastic tube the tonsil is developed. According to Gulland the lymphoid tissue is developed directly from the hypoblastic cells and not, as was previously thought, from mesoblastic cells growing round the tube. The outlet of the tube is narrowed by two triangular folds of mucous membrane. One of these stretches between the pillars in the angle formed by their junction with the soft palate. This is known as the plica semilunaris. A second fold stretches backwards from the anterior pillar of the fauces. It has a free crescentic margin behind and at its lower part is attached to the tonsil. This is known as the plica triangularis.

In the human foetus of four months the tonsil appears as an oval mass which is divided into an anterior and a posterior portion by a ridge. This ridge rises up as an evagination from the floor of the mass with a gronve on either side of it. Lymphoid tissue is developed at the bottom of each groove round multiple diverticula from the

2 A Note on the Rarity of Hydatid Disease in Egypt, Intercolonia Medical Journal of Australasia, March 20th, 1904. hypoblast lining it. At birth the lymphoid tissue has extended to the surface on each side of the grooves and also over the intervening ridge. The tonsil at birth consists of three tonsillar masses with two furrows between them. These furrows, which are the remains of the cavities of the anterior and posterior tonsillar sacs, are directed upwards and forwards towards the supratonsillar fossa. The middle tonsillar mass consists of the ridge with the adjacent lips of the anterior and posterior tonsillar sacs. The anterior and posterior masses consist of the lymphoid tissue in front of and behind the grooves respectively.

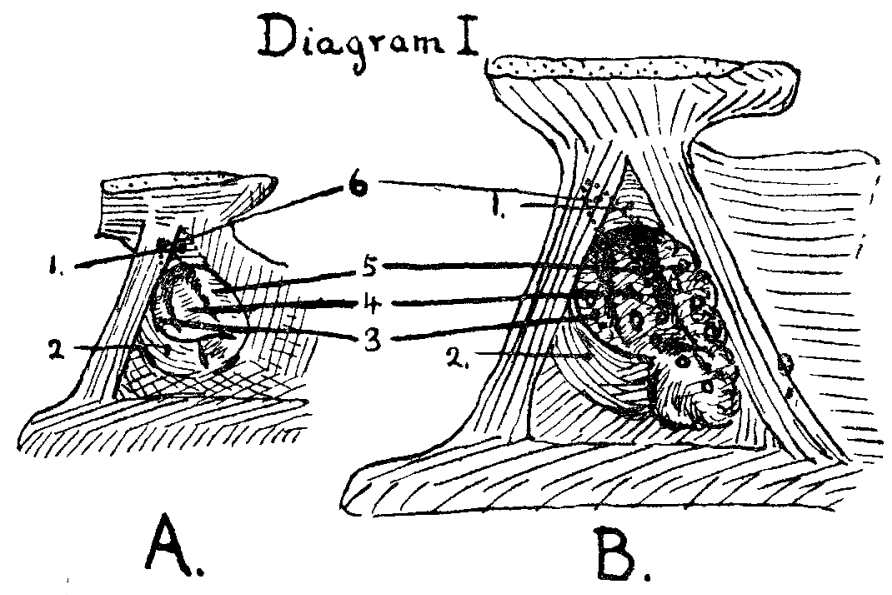

A. Tonsil of seven months fotus. B. Tonsil of four years old child. 1. Plica semilunaris. 2. Plica triangularis. 3, 4,5 . Anterior, middle, and posterior tonsillar masses. 6. Dotted line showing position of supratonsillar fossa.

The plica triangularis blends with the middle tonsillar mass and as it does so it divides into two. One portion passes toward the side of the tongue, while the other cuts across the middle mass, dividing it into an upper and a lower portion. These two folds are known respectively as the plica prætonsillaris and plica infratonsillaris (Killian). (See Diagram I., A.) The plica triangularis persists in a large number of cases in the adult. After birth the tonsils proliferate unevenly, so that the lymphoid tissue may project from anterior or posterior tonsil sac and the grooves be obliterated, or one or the other of the tonsillar masses may be developed out of proportion to the other and form the main tonsillar mass.

The supratonsillar fossa persists in a large proportion, if not in all cases, as a narrow passage extending in an upward and slightly forward direction under cover of the soft palate for $1-2$ centimetres, the plica semilunaris remaining as its inner wall. (See Diagram I., B.) The crypts of the tonsils represent the original budding out of the hypoblast from the lining wall of the diverticulum round which the lymphoid tissue is developed. They originally opened into the grooves which represent the cavities of the anterior and posterior cups, but during the process of lymphoid proliferation these grooves are obliterated to a greater or lesser extent, so that the crypts open on the free surface of the tonsillar mass. In man some of the crypts open into the supratonsillar fossa. This is to be explained by the fact that in many animals the channel which in man is represented by the supratonsillar fossa is completely surrounded by lymphoid tissue.

In addition to the main tonsil there are accessory lymphoid nodules, of which the most constant are a number of scattered lymphoid masses which pass from the main tonsil towards the side of the tongue. They are interspersed among the mass of mucous glands and tongue papillæ, and the combined mass reaches to the mid-line of the tongue, in front of the epiglottis, and meets its fellow of the other side. This mass I call the lingual prolongation. In some cases there are lymphoid follicles on the deep surface of the plica triangularis and in others they may be found on its pharyngeal aspect. (See Diagram IV., D 1.)

Owing to the courtesy of Dr. P. Chalmers Mitchell, secretary, and Mr. F. E. Beddard, prosector, of the Zoological Society, I have been able to examine the pharynges of 100 species of mammals which came to the post-mortem table at the prosectorium of the society. The tonsils of mammals present a very interesting evolutionary series. They show many of the stages which can be geen in its development in the human embryo. The following diagrams (Diagram II.), which are drawn from sections through the long axis of a series of mammalian tonsils, illustrate the distribution and 